\title{
Dermatological manifestations and medico-social correlates among intellectually disabled students in Central India
}

\author{
Harshal Gupta ${ }^{1}$, Vishal Agrawal ${ }^{2}$ \\ ${ }^{1}$ Associate Professor, ${ }^{2}$ Private Practitioner, Department of Community Medicine, Sri Aurobindo Institute of Medical \\ Sciences, Indore (MP), India
}

\section{A B S T R A C T}

Background: People with intellectual disabilities (PwID) are particularly more vulnerable to dermatological manifestations due to their associated disabilities and hygiene negligence. Aims and Objective: To estimate the prevalence and pattern of skin diseases considering various medico-social correlates among PwID in two districts of Central India. To apply multinomial logistic regression analysis to examine the medico-social factors associated with no, one and more than one dermatological manifestations. Materials and Methods: A total of 204 PwID receiving rehabilitation services under a NGO serving two districts were examined for dermatological manifestations and various medico-social factors were studied. Descriptive analysis like chi-square and multinomial logistic regression analysis (MLR) was performed. Results: We found that $87.25 \%$ of study participants had one or more dermatological manifestations \{infectious $(64.7 \%)$ and non-infectious $(84.3 \%)$ \}. Among the various medico-social variables studied, socio-economic status, education of parents and associated co-morbidities were independently associated with increase in frequency of skin disorders. MLR analysis showed that Illiteracy of parents, lower socio-economic status and associated co-morbidities in PwID had higher odds of developing one and more than one dermatological manifestations when compared to literate and high income families and PwID with no associated co-morbidities. Conclusion: This study delineates the importance of additional attempts to be made by dermatologist while dealing with PwID while considering carefully their associated co-morbidities and various social factors. Strict hygiene measures, periodic skin examination and health education of persons caring for students with disabilities are recommended.

Key words: Skin disorders; Intellectual disability; Infectious skin; Health education; Dermatological manifestations

\section{INTRODUCTION}

Dermatological manifestations accounts for $10-20 \%$ of all the consultations in general practice. ${ }^{1}$

Growing severity of skin diseases in India is further emphasized by World Health Organization which has included skin diseases under the most common noncommunicable diseases. ${ }^{2}$ Skin diseases are among the most common diseases in school children globally. ${ }^{3}$ The situation is further worsened in children with disabilities especially intellectual disabilities (ID) ${ }^{4}$ as health conditions of these persons is a neglected subject especially in Indian context, despite the evidence that these individuals experience poorer health (due to associated co-morbidities), shorter lifespan, and less access to professional health care than people without this condition. ${ }^{5}$ Intellectual disability is a generalized neuro-developmental disorder characterized by significantly impaired intellectual and adaptive functioning and an IQ score under 70 with a prevalence of $1-3 \%$ 
globally. ${ }^{6,7}$ Available published literature cites that Person with intellectual disability (PwID) are more likely to have various health problems including skin disorders compared with the general population due to their associated comorbidities and restricted movements. ${ }^{8}$ As per our review, there is a paucity of available information concerning the prevalence and pattern of skin disorders in relation to various medico-social correlates in PwID. With the rising incidence of dermatological manifestations in PwID, it is essential to understand how the disease burden is shared among PwID with increasing frequency of skin, hair and nail lesions. There is a need for modeling of risk process for increasing frequency of dermatological manifestations in PwID with respect to various medico-social factors. This is essential for better planning of comprehensive dermatological manifestations treatment services in PwID. The broad purpose of this study was to present a detailed overview of the specific skin, hair and nail problems along with its correlation to medico-social factors in children with ID.

\section{MATERIAL AND METHODS}

\section{Study design}

The present study was designed as a part of a health check up camp organized by the researcher among all children with intellectual disability receiving rehabilitation services under a NGO serving Ujjain and Shajapur districts of Madhya Pradesh. The authors have previous publicationwhere they have studied various medico-social predictors of school performance on the same study subjects. ${ }^{9}$ This Study was a follow up study over one academic year (July 2011-April 2012). The study was performed at two purposively selected districts i.e. Ujjain and Shajapur districts of Madhya Pradesh, India. At the time of study there were total five prevocational rehabilitation centers for PwID in selected districts (three in Ujjain and two in Shajapur). The study was conducted at the four centers run by NGO included in the study. Two Study centers are located in Ujjain district and two are located in Shajapur district of Madhya Pradesh. The present study was designed as a part of a health check up camp organized by the researcher among all the students studying at selected centers were included in the study. Students with profound mental retardation, whose parents didn't consent and who couldn't complete one academic year after start of study were excluded from the study. A total of $204(92.3 \%)$ students out of 221 enrolled fulfilled the inclusion criteria from all study settings.

\section{Methodology}

The principal investigator met all the school authorities and explained them the nature of this study to seek their consent. The researchers have organized camps within the school premises especially during the regular parent-teacher meet. Verbal consent for participation in the study was taken from parents. All the study participants were assessed for their skin, hair and nail related problems in-depth by the health professional. During teacher-parent meetings, socio-demographic details were collected from parents of study subjects with the help of class teachers. Medical problems of PwID like epilepsy, hyperkinesis, associated psychiatric and behavioral manifestations along with associated handicap viz. physical disabilities due to cerebral palsy, deaf/dump or blind were interviewed from parents and school medical records of students were verified. Help of school appointed Psychologist was taken.

\section{Socio-demographic variables quantification}

Age of student's ranged from 4 to 34 years with mean age 13.02 , where $69.1 \%$ were males. Each adolescent was assigned to one of the two types of family arrangements: first were intact families or both natural parents. Second being non intact families or one natural parent only, one natural parent and a stepparent or neither of parent or the child is staying with some relative as caretaker. Parents' education levels: Measures of both mother's and father's levels of education had three categories: (a) elementary level and a few years at the high school level (b) high school completed, and (c) college or university graduated. These measures were averaged to create a single parental education measure that had five categories: (1) both parents who are college or university graduated. (2) one of the parents with high school completed and the other one who is college or university graduated; (3) both parents with high school completed; (4) one parents with elementary level or few years at the high school; the other parent with high school completed and (5) both parents with elementary level or few years at high school; About the socio-economic status, Kuppuswamy classification was followed and families were divided into five categories. Associated co-morbidities are included where co-morbidity is either absent or present and is counted as one or more than one disability.

\section{Ethical considerations}

Protocol of the study was approved by Ethics committee of the institute. Information sheet was undersigned by NGO Head. Written informed consent was taken from parents. Analysis was done using SPSS 20.

\section{Analysis}

Analysis was done using SPSS 20. Statistical test were used where ever applicable.

\section{RESULT}

The study observed that $87.25 \%$ of mentally retarded students had 1 or more skin diseases (both infectious 
and non-infectious). The most common of which were Peduculosis capitis (31.37), Pitariasis sicca (23.52), Impetigo (15.68), Acne vulgaris and acne excories (14.21) and so on (Table 1).

Table 2 shows the distribution of frequency of skin disorders according to medico-social characteristics of study participants. Results indicate that among all the medico-social variables, socio-economic status, education of parents and associated co-morbidities were significantly associated with increase in number of skin disorders.

\begin{tabular}{|c|c|c|}
\hline Skin disorder & Number $(n=204)$ & $\%$ \\
\hline No & 26 & 12.74 \\
\hline Yes & 178 & 87.25 \\
\hline \multicolumn{3}{|l|}{ Infectious } \\
\hline No & 72 & 35.29 \\
\hline Yes & $132^{*}$ & 64.71 \\
\hline Bacterial & $42^{*}$ & 20.58 \\
\hline Impetigo & 32 & 15.68 \\
\hline Boils \& folliculitis & 10 & 4.9 \\
\hline Furuncle & 2 & 0.98 \\
\hline Parasitic & $67^{*}$ & 32.84 \\
\hline Pediculosis capitis & 64 & 31.37 \\
\hline Scabies & 8 & 3.92 \\
\hline Fungal & $16^{*}$ & 7.84 \\
\hline Tinea capitis & 6 & 2.9 \\
\hline Tinea versicolor & 6 & 2.9 \\
\hline Tinea pedis & 4 & 1.96 \\
\hline Onychomycosis & 4 & 1.96 \\
\hline Pityriasis versicolor & 8 & 3.92 \\
\hline Viral & $5^{*}$ & 2.45 \\
\hline Wart & 3 & 1.47 \\
\hline Herpes simplex & 2 & 0.98 \\
\hline Mixed & $11^{*}$ & 5.39 \\
\hline Intertrigo & 11 & 5.39 \\
\hline \multicolumn{3}{|l|}{ Non-infectious } \\
\hline No & 32 & 15.68 \\
\hline Yes & $172^{*}$ & 84.31 \\
\hline Acne vulgaris and acne excories & 29 & 14.21 \\
\hline Eczema & 15 & 7.35 \\
\hline Lichen simplex chronicus & 11 & 5.39 \\
\hline Pigmentatory disorder (hyper hypo) & 24 & 11.76 \\
\hline Alopecia areata & 9 & 4.41 \\
\hline Androgenitic alopecia & 8 & 3.92 \\
\hline Dermatitis artifacta and neglacta & 6 & 2.94 \\
\hline Pitariasis sicca & 48 & 23.52 \\
\hline History suggestive of urticaria & 4 & 1.96 \\
\hline Ichtyosis vulgaris & 1 & 0.49 \\
\hline Phrynoderma & 8 & 3.92 \\
\hline Psoriasis & 2 & 0.98 \\
\hline Vitiligo & 3 & 1.47 \\
\hline Seborrhic dermatitis & 10 & 4.90 \\
\hline Miliaria & 12 & 5.88 \\
\hline Atopic dermatitis & 4 & 1.96 \\
\hline Nail biting disorder (onychophagia) & 24 & 11.76 \\
\hline Tic deformity & 2 & 0.98 \\
\hline Onychotillomania & 8 & 3.92 \\
\hline
\end{tabular}

Table 3 showed Multinomial logistic regression analysis for frequency of skin lesions (one, more than one) controlled for various medico-social factors. First half of the table describes the medico social factors associated with occurrence of one dermatological manifestation in PwID. When compared to Upper SES, PwID belonging to Lower middle SES had an Odds Ratio (OR=21.12; $\mathrm{p}=0.021$ ), Middle lower middle SES had an Odds Ratio $(\mathrm{OR}=62.495 ; \mathrm{p}=0.003)$ and in PwID from Upper middle SES had an Odds Ratio (OR=14.84; $\mathrm{p}=0.012)$. PwID with one associated disability had an Odds Ratio (OR $=11.78$; $\mathrm{p}=0.011)$ when compared with no associated disability for occurrence of one dermatological manifestation.

While second half of the table describes the medico social factors associated with occurrence of more than one dermatological manifestation in PwID. When compared to Upper SES, PwID belonging to Middle lower middle SES had an Odds Ratio (OR=47.63; $\mathrm{p}=0.003)$ and in PwID from Upper middle SES had an Odds Ratio $(\mathrm{OR}=8.71$; $\mathrm{p}=0.023)$. More over parents with cat 5 education had an Odds Ratio $(\mathrm{OR}=12.07 ; \mathrm{p}=0.042)$ when compared to cat 4 parent education of PwID. Also when compared with PwID having no associated lesion, PwID with one associated disability had an Odds Ratio (OR $=11.78$; $\mathrm{p}=0.011)$ and with more than one associated disability had an Odds Ratio $(\mathrm{OR}=11.78 ; \mathrm{p}=0.011)$ for occurrence of more than one dermatological manifestation.

\section{DISCUSSION}

The focus of the study on children with ID is justified by the fact that they are a vulnerable sector of the community with associated co-morbidities and high prevalence of dermatological manifestations. ${ }^{3,5,6}$ Majority of the published studies are focusing on prevalence and pattern of skin disorders in intellectually disabled without considering the unique medical, social and behavioral disorders common to this population. This study was thus planned owing to the relative scarcity of data specific to this group with reference to pattern of skin disorders while considering various medico-social correlates especially in a developing country. In the present study, influence of associated co-morbidities and the family demographics of PwID on the increasing frequency of dermatological manifestations were also studied.

The preliminary descriptive analysis has observed that proportion of study subjects who had 1 or more skin diseases (both infectious and non-infectious) were found to be $87.25 \%$ (178 out of 204 ) in comparison to $24.2 \%{ }^{2}$ and $31.3 \%{ }^{10}$ of the prevalence of skin condition in students from regular schools as mentioned in various 
Table 2: Distribution of frequency of skin disorders according to socio-demographic characteristics of study participants

\begin{tabular}{|c|c|c|c|c|c|c|}
\hline \multirow[t]{2}{*}{ Variables } & \multicolumn{3}{|c|}{ Associated skin disorders } & \multirow[t]{2}{*}{ Total $(n=204)$} & \multirow[t]{2}{*}{ Chi-square } & \multirow[t]{2}{*}{ p-value } \\
\hline & No $(n=26)$ & One $(n=42)$ & $>$ one $(n=136)$ & & & \\
\hline \multicolumn{7}{|l|}{ Age } \\
\hline $0-5$ & 3 & 7 & 9 & 19 & 8.488 & 0.387 \\
\hline $6-10$ & 9 & 10 & 57 & 76 & & \\
\hline $11-15$ & 8 & 16 & 39 & 63 & & \\
\hline $16-20$ & 5 & 7 & 28 & 40 & & \\
\hline$>20$ & 1 & 2 & 3 & 6 & & \\
\hline \multicolumn{7}{|l|}{ Gender } \\
\hline Male & 18 & 28 & 95 & 141 & 0.153 & 0.926 \\
\hline Female & 8 & 14 & 41 & 63 & & \\
\hline \multicolumn{7}{|l|}{ Type of family } \\
\hline Nuclear family & 11 & 27 & 77 & 115 & 5.96 & 0.202 \\
\hline Third generation family & 9 & 6 & 23 & 38 & & \\
\hline Joint family & 6 & 9 & 36 & 51 & & \\
\hline \multicolumn{7}{|l|}{ Socio-economic status } \\
\hline Upper & 9 & 3 & 8 & 19 & 20.83 & $0.008^{*}$ \\
\hline Upper middle & 7 & 16 & 40 & 63 & & \\
\hline Middle lower middle & 3 & 11 & 40 & 54 & & \\
\hline Lower upper lower & 6 & 11 & 44 & 61 & & \\
\hline Lower & 2 & 1 & 4 & 7 & & \\
\hline \multicolumn{7}{|l|}{ Education of parents } \\
\hline Category 1 & 9 & 8 & 12 & 29 & 19.38 & $0.013^{*}$ \\
\hline Category 2 & 3 & 10 & 19 & 32 & & \\
\hline Category 3 & 4 & 10 & 36 & 50 & & \\
\hline Category 4 & 8 & 10 & 39 & 57 & & \\
\hline Category 5 & 2 & 4 & 30 & 36 & & \\
\hline \multicolumn{7}{|l|}{ Family structure } \\
\hline Intact families & 25 & 34 & 123 & 182 & 4.49 & 0.106 \\
\hline Non intact families & 1 & 8 & 13 & 22 & & \\
\hline \multicolumn{7}{|l|}{ Severity of retardation } \\
\hline Mild & 10 & 18 & 49 & 77 & 3.34 & 0.503 \\
\hline Moderate & 13 & 19 & 57 & 89 & & \\
\hline Severe & 3 & 5 & 30 & 38 & & \\
\hline \multicolumn{7}{|l|}{ Associated disability } \\
\hline No association & 22 & 23 & 51 & 96 & 26.27 & 0.00 \\
\hline One disability & 3 & 16 & 46 & 65 & & \\
\hline More than one disability & 1 & 3 & 39 & 43 & & \\
\hline \multicolumn{7}{|l|}{ Epilepsy } \\
\hline Present & 1 & 3 & 22 & 26 & 4.477 & 0.107 \\
\hline Absent & 25 & 39 & 114 & 178 & & \\
\hline \multicolumn{7}{|l|}{ Hyperkinesis } \\
\hline Present & 0 & 2 & 24 & 26 & 9.143 & 0.010 \\
\hline Absent & 26 & 40 & 112 & 178 & & \\
\hline \multicolumn{7}{|l|}{ Psychiatric manifestations } \\
\hline Present & 0 & 5 & 20 & 25 & 4.396 & 0.111 \\
\hline Absent & 26 & 37 & 116 & 179 & & \\
\hline \multicolumn{7}{|l|}{ Associated handicap } \\
\hline Present & 1 & 2 & 24 & 27 & 6.927 & 0.031 \\
\hline Absent & 25 & 40 & 112 & 117 & & \\
\hline \multicolumn{7}{|l|}{ Clinical syndromes } \\
\hline Present & 0 & 1 & 13 & 14 & 4.782 & 0.092 \\
\hline Absent & 26 & 41 & 123 & 190 & & \\
\hline Associated behavioral diso & & & & & & \\
\hline Present & 4 & 9 & 28 & 41 & 0.426 & 0.808 \\
\hline Absent & 22 & 33 & 108 & 16 & & \\
\hline
\end{tabular}

other studies. ${ }^{8,11}$ Similarly, a study by Fathy et.al reported high proportions of skin diseases in PwID. ${ }^{3}$ The reason for higher dermatological manifestations in PwID might attribute to facts that skin lesions that could annoy a person without ID often goes unnoticed for PwID. Additionally, lifelong dependence of these children on caretaker is observed which is even more in PwID with associated motor disabilities. This attributes to poor personal hygiene of PwID which is indirectly dependent on caretaker's attitude towards hygiene and standard of living.

In the present study prevalence of infectious skin diseases was found to be higher in PwID than the prevalence in children from general population reported in other studies. ${ }^{11}$ The habit 


\begin{tabular}{|c|c|c|c|c|c|c|}
\hline \multirow{2}{*}{$\begin{array}{l}\text { Dermatological manifestations } \\
\text { (ref: no manifestation) }\end{array}$} & \multirow[t]{2}{*}{ B } & \multicolumn{2}{|c|}{ One manifestation } & \multirow[t]{2}{*}{ B } & \multicolumn{2}{|c|}{ More than one manifestation } \\
\hline & & $\operatorname{Exp}(B)$ & p-value & & $\operatorname{Exp}(B)$ & $p$ value \\
\hline Intercept & 2.573 & & 0.083 & _3.741 & & 0.008 \\
\hline Age $>20$ & 1.571 & 4.813 & 0.395 & 1.040 & 2.829 & 0.570 \\
\hline Age $16-20$ & 0.827 & 2.287 & 0.471 & 2.101 & 8.175 & 0.057 \\
\hline Age $11-15$ & 1.089 & 2.971 & 0.302 & 1.933 & 6.910 & 0.063 \\
\hline Age $6-10$ & 0.106 & 1.112 & 0.919 & 1.873 & 6.510 & 0.063 \\
\hline Age $<5$ & 0 & & & 0 & & \\
\hline Male gender & 0.461 & 0.631 & 0.514 & 0.205 & 0.814 & 0.227 \\
\hline Female gender & 0 & & & 0 & & \\
\hline Joint family & _0.743 & 0.476 & 0.365 & 0.360 & 0.698 & 0.638 \\
\hline Third generation family & -1.871 & 0.154 & 0.017 & 1.876 & 0.153 & 0.008 \\
\hline Nuclear family & 0 & & & 0 & & \\
\hline Lower SES & 1.069 & 2.912 & 0.574 & 0.227 & 0.797 & 0.887 \\
\hline Lower middle SES & 3.050 & 21.118 & 0.021 & 2.302 & 9.998 & 0.051 \\
\hline Middle lower middle SES & 4.135 & 62.495 & 0.003 & 3.863 & 47.628 & 0.003 \\
\hline Upper middle SES & 2.697 & 14.836 & 0.012 & 2.164 & 8.709 & 0.023 \\
\hline Upper SES & 0 & & & 0 & & \\
\hline Non-intact family & 1.826 & 6.208 & 0.160 & 1.120 & 3.066 & 0.388 \\
\hline Intact family & 0 & & & 0 & & \\
\hline Severe MR & 0.880 & 0.415 & 0.370 & 0.125 & 1.134 & 0.886 \\
\hline Moderate MR & 0.238 & 0.789 & 0.746 & 0.082 & 1.086 & 0.903 \\
\hline Mild MR & 0 & & & 0 & & \\
\hline Parent education Cat 5 & $0.628-0$ & 1.874 & 0.648 & 2.490 & 12.067 & 0.042 \\
\hline Parent education Cat 4 & -462 & 0.630 & 0.685 & 0.463 & 1.590 & 0.646 \\
\hline Parent education Cat 3 & $\overline{0.756}$ & 2.130 & 0.500 & 1.742 & 5.709 & 0.089 \\
\hline Parent education Cat 2 & 1.879 & 6.548 & 0.097 & 1.917 & 6.799 & 0.078 \\
\hline Parent education Cat 1 & 0 & & & 0 & & \\
\hline More than one disability & 1.421 & 4.142 & 0.266 & 3.262 & 26.092 & 0.004 \\
\hline One associated disability & 2.466 & 11.779 & 0.011 & 3.063 & 21.392 & 0.001 \\
\hline Without associated disability & 0 & & & 0 & & \\
\hline
\end{tabular}

of repetitive scratching of skin and self-injurious behavior observed in PwID might facilitate the spread of bacterial infections. Similar relation was depicted in a study by Cotterill et al who suggested that low resistance might be responsible for pyogenic skin infection among mentally retarded people. ${ }^{12}$ Pediculosis capitis was identified with high prevalence in PwID. Similar findings were reported by Ismail et al in their study. ${ }^{13}$ Similarly, fungal infections like Tinea capitis, Tinea versicolor and viral infections like Warts were reported with high prevalence in PwID. These results of higher infectious skin condition in study population are in agreement to findings of a study by Fathy et $\mathrm{al}^{3}$ who did a comparative study of PwID with a control from general population and found a higher prevalence in PwID. In this study, the prevalence of noninfectious skin conditions was $84.31 \%$ and is not dissimilar with results of previous studies., ${ }^{3,12}$ Similarly, Fathy et al. in their studies reported lower prevalence in children without ID. ${ }^{3}$ The reasons which explain these high rates are both the nature of the disability and the associated day-to-day problems. The repeated habit of scratching, frequent susceptibility to trauma and observed dry skin was the other observed reasons. Moreover, such disease may reflect nutritional deficiency and negligence on the part of caretakers of PwID or it may reflect their low socioeconomic standards.
Prevalence of hair changes like alopecia areata and cicatricial alopecia are also high in this group. This may attribute to medications for associated epilepsy, stressful life event and more susceptibility to trauma. Leukonychia and onychophagia were found more prevalent in PwID. Frequent trauma explains prevalence of leukonychia while the nature of disease itself explains higher prevalence of onychophagia in PwID. The above evidence of high prevalence of skin diseases in PwID suggests that the quality of health services they receive is often inadequate and not frequently enough. Also these evidences suggest that PwID do not have a good health care access. ${ }^{14}$

The medico-social variables independently associated with increase in frequency of skin disorders in this study are socio-economic status, education of parents and associated co-morbidities. We observed that students with a poorer socio-economic environment especially regarding infectious diseases, skin morbidities are higher. Students with more educated parents in this study had lesser frequency of skin manifestations. The explanations can be partly because educated parents support them to get timely management of these conditions and their belief in importance of maintaining hygiene especially in PwID. Study subjects with associated co-morbidities like physical and mental (other 
psychiatric manifestations) also found to have increased dermatological manifestations. This finding is in conformity with the findings from the previous systematic review which documented that prevalence of skin diseases are more in patient with psychiatric manifestations. ${ }^{15}$ It is important from community health's point of view to assess not only the prevalence of skin disease, but also to identify associated medico-social factors and consider it while treating PwID.

It is essential to identify high risk population and to target their associated co-morbidities to improve the treatment approach towards them. Therefore multinomial regression analysis was used to assess the significant independent factors associated with increasing frequency of dermatological manifestations in PwID. Factors like illiteracy of parents, lower socio-economic status and associated co-morbidities in PwID had higher odds of developing one and more than one dermatological manifestations when compared to literate and high income families and PwID with no associated co-morbidities.

\section{CONCLUSION}

Primary medical care of PwID should involve continuity of care, maintenance of comprehensive treatment documentation, routine periodic health screening and understanding of the unique medical and behavioral disorders common to this population. For the dermatologist the first approach would be treatment of the skin lesions but they often lack therapeutic strategies to deal with PwID. This study delineates the importance of additional attempts to be made by dermatologist while dealing with PwID and also to explain simple and efficacious preventive actions to their parents like self care and hygiene improvement. This study can potentially support in identifying the lacunae pertaining to treatment initiation by a dermatologist in PwID, where medico-social factors needs to be considered. Strict hygiene measures, periodic skin examination and health education of persons caring for students with disabilities are recommended.

\section{REFERENCES}

1. Patel NG and Patel NJ. Epidemiological study of skin (dermatological) diseases and its treatment in North Gujarat.
Asian J Pharm Clin Res 2010; 3 (4).

2. Amaro-Ortiz A, Yan B and D'Orazio JA. Ultraviolet radiation, aging and the skin: Prevention of damage by topical cAMP manipulation. Molecules 2014; 19: 6202-6219.

3. Fathy H, El-Mongy S, Baker N.I, Abdel-Azim, Z and El-Gilany A. Prevalence of skin diseases among students with disabilities in Mansoura, Egypt. East Mediterr Health J 2004; 10: 416-424.

4. Colin T. General Learning Disability. The term general learning disability has now been recommended in the UK to replace terms such as mental handicap or mental retardation; 25 January, 2013. Available from: http://www.Patient.info. [Last accessed on 2018 Jun 17].

5. Jansen DE, Krol B, Groothoff JW and Post D. People with intellectual disability and their health problems: a review of comparative studies. J Intellect Disabil Res 2004; 48: 93-102.

6. Ahmed N, Joshi H, Bano R and Phalke D. Study of health status and etiological factors of mentally challenged children in a school for mentally challenged in rural Maharashtra. Internet Journal of Medical Update 2010; 5:21-25.

7. Roeleveld $\mathrm{N}$ and Zielhuis GA. The prevalence of mental retardation: A critical review of recent literature. Dev Med Child Neurol 1997; 39: 125-132.

8. Fung WK and Lo KK. Prevalence of Skin Disease among School Children and Adolescents in a Student Health Service Center in Hong Kong. Pediatric Dermatology 2001; 17:440-446.

9. Gupta H and Sabde Y. Medicosocial characteristics as predictors of school achievements in students with intellectual and developmental disabilities: A follow-up study in Ujjain and Shajapur districts of Madhya Pradesh, India. Indian J Public Health 2018; 62, 39-46.

10. Inanir I, Sahin MT, Gunduz K, Dinc G, Turel A and Ozturkan S. Prevalence of skin conditions in Primary school children in Turkey: Differences based on socio-economic factors: Pediatr Dermatol 2002;19:307-11.

11. Van Schrojenstein Lantman-De Valk HMJ, Metsemakers JFM, Haveman MJ and Crebolder HFJM. Health problems in people with intellectual disability in general practice: A comparative study. Family Practice 2000; 17: 405-407.

12. Cotterill JA, Millard LG. Psychocutaneous disorders. In: Champion RH, Burton JL, Burns A.D, eds. Textbook of dermatology, $6^{\text {th }}$ ed. Oxford: Blackwell Scientific Publications; 1998. p. 2785-2797.

13. Ismail EA. Skin change in the mentally retarded children in Alexandria. Journal of the Pan-Arab League of Dermatologists, 1997; 8(2):115.

14. Cooper SA, Morrison J, Melville C, Finlayson J, Allan L, Martin G, et al. Improving the health of people with intellectual disabilities: outcomes of a health screening programme after 1 year. J Intellect Disabil Res 2006; 50: 667-677.

15. Nayera H. Moftah A, Abeer M. Kamel A, Hussein M. Attia B, Mona Z. El-Baz C and Hala M. Abd El-Moty. Skin diseases in patients with primary psychiatric conditions: A hospital based study. J Epidemiol Glob Health 2013; 3: 131-138.

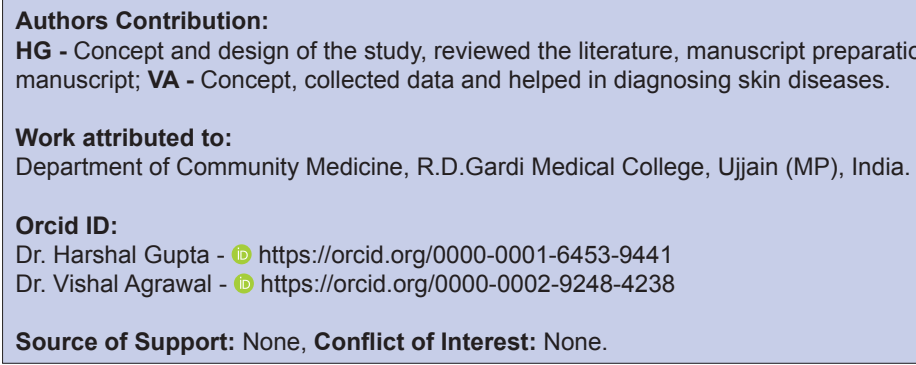

